\title{
The inhibition of cell proliferation and induction of apoptosis in pancreatic ductal adenocarcinoma cells by verrucarin $A$, a macrocyclic trichothecene, is associated with the inhibition of $\mathrm{Akt} / \mathrm{NF}-\mathrm{kB} / \mathrm{mTOR}$ prosurvival signaling
}

\author{
DORRAH DEEB $^{1}$, XIAOHUA GAO $^{1}$, YONGBO LIU $^{1}$, YIGUAN ZHANG $^{2}$, \\ JIAJIU SHAW ${ }^{2}$, FREDERICK A. VALERIOTE ${ }^{2}$ and SUBHASH C. GAUTAM ${ }^{1}$ \\ Departments of ${ }^{1}$ Surgery and ${ }^{2}$ Internal Medicine, Henry Ford Health System, Detroit, MI, USA
}

Received April 19, 2016; Accepted June 16, 2016

DOI: 10.3892/ijo.2016.3587

\begin{abstract}
Pancreatic ductal adenocarcinoma (PDA) remains one of the most difficult to treat of all malignancies. Multimodality regimens provide only short-term symptomatic improvement with minor impact on survival, underscoring the urgent need for novel therapeutics and treatment strategies for PDA. Trichothecenes are powerful mycotoxins that inhibit protein synthesis and induce ribotoxic stress response in mammalian cells. Verrucarin A (VC-A) is a Type D macrocyclic mycotoxin which inhibited cell proliferation and induced apoptosis in breast cancer cells. However, the antitumor activity of VC-A for PDA cells has not been investigated. Here we show potent antitumor activity and the mechanism of action of VC-A in PDA cell lines. VC-A strongly inhibited the proliferation and arrested cells in the $\mathrm{S}$ phase of the cell cycle. The blocking of cell cycle progression by VC-A was associated with the inhibition of cell cycle regulatory proteins cyclin D1, cyclin E, cyclin-dependent kinases (cdks) cdk2, cdk4 and cdk inhibitor WAF1/21. VC-A induced apoptosis in PDA cells as indicated by the increased Annexin V FITC-binding, cleavage of poly(ADP-ribose) polymerase-1 (PARP-1) and procaspases-3, -8 and -9 . VC-A also induced mitochondrial depolarization and release of cytochrome $c$ and it inhibited Bcl-2 family proteins that regulate apoptosis (Bcl-2, Bcl-xL, $\mathrm{Bax}$ and $\mathrm{Bad})$. In addition, $\mathrm{VC}-\mathrm{A}$ reduced the levels of inhibitors of apoptosis survivin and c-IAP-2. Finally, VC-A downregulated the expression of prosurvival phospho-Akt (p-Akt), nuclear factor $\kappa \mathrm{B}(\mathrm{NF}-\mathrm{\kappa B})(\mathrm{p} 65)$ and mammalian target of rapamycin (p-mTOR) signaling proteins and their downstream mediators. Together, these results demonstrated
\end{abstract}

Correspondence to: Professor Subhash C. Gautam, Department of Surgery, Henry Ford Health System, 4D, One Ford Place, Detroit, MI 48183, USA

E-mail:sgautam1@hfhs.org

Key words: pancreatic ductal adenocarcinoma, verrucarin A, apoptosis, Akt, NF-kB, mTOR strong antiproliferative and apoptosis-inducing activity of verrucarin A for PDA cells through cell cycle arrest and inhibition of the prosurvival (antiapoptotic) $\mathrm{AKT} / \mathrm{NF}-\kappa \mathrm{B} / \mathrm{mTOR}$ signaling.

\section{Introduction}

Pancreatic ductal adenocarcinoma (PDA) is almost uniformly lethal with an estimated annual number of 45,220 new cases approximating 38,460 annual deaths and a 5-year survival rate of $<5 \%$ (1-3). Late initial diagnosis, aggressive metastatic behavior and resistance to chemoradiotherapy render pancreatic cancer one of the most difficult to treat of all malignancies. Surgical resection is potentially curative in a minority of patients; however, $>80 \%$ of the patients are diagnosed with locally advanced disease that precludes surgical intervention. Systemic gemcitabine alone or in combination with 5-FU, irinotecan and oxaliplatin (FOLFIRINOX) is the current standard of care for advanced pancreatic cancer, providing short-term symptomatic improvement with minor impact on survival (4-6). Thus, there is an urgent need for developing novel agents for the treatment of pancreatic cancer.

Trichothecenes are structurally related low molecular weight sequiterpenoid metabolites produced by filamentous fungi, such as Myrothecium, Stachybotrys, Fusarium and others (7). Trichothecenes are potent mycotoxins that are believed to be responsible for adverse respiratory and neurological effects of damp and moldy indoor environments (8-10). They elicit a wide range of biological responses in eukaryotic cells, including inhibition of protein synthesis and cell proliferation; induction of cytotoxicity, ribotoxic stress responses and modulation of immune responses (11-16). Verrucarin A (VC-A) is a macrocyclic trichothecene that evokes strong antiproliferative and proapoptotic responses in cancer cells (17-20). There is some evidence that the antiproliferative and apoptosis-inducing effects of VC-A are due to the inhibition of protein synthesis through blocking of peptidyl transferase activity and activation of c-jun N-terminal kinase (c-JNK) and p-38 MAP kinase $(14,17,18)$.

In a previous report, VC-A was identified as a major mediator of the anticancer activity in salt water cultures of 
Myrothecium verrucaria isolated from a sponge species collected in Hawaii (21). However, the mode of cell death or the mechanism by which VC-A kills tumor cells was not investigated in that study.

In this study, we investigated the anticancer activity of verrucarin A against PDA cell lines. Data showed that VC-A inhibits the proliferation and induces cell cycle arrest in $\mathrm{S}$ phase by inhibiting cell cycle-related regulatory proteins. VC-A induced apoptosis in PDA cells through the activation of procaspases, induction of mitochondrial depolarization and inhibition of Bcl-2 and IAP family of proteins that regulate apoptosis. In addition, VC-A also inhibited prosurvival signaling proteins (e.g., p-Akt, NF-KB and p-mTOR) and their downstream mediators.

\section{Materials and methods}

Reagents. Verrucarin A isolated from salt water cultures of Myrothecium verrucaria separated from Spongia Sp. was obtained from Dr Phillip Crews, University of California, Santa Cruz. Anti-caspase-3, caspase-8, and caspase-9 antibodies were purchased from BD Pharmingen (San Diego, CA, USA). Antibodies against p-Akt $\left(\operatorname{ser}^{473}\right)$, p-mTOR $\left(\operatorname{Ser}^{2448}\right)$, PARP-1, anti-NF- $\mathrm{B}$ (p65), anti-Bcl-2, anti-Bcl-xL, anti-Bax, anti-Bak, anti-Bad and $\beta$-actin were purchased from Santa Cruz Biotechnology, Inc. (Santa Cruz, CA, USA). Anti-cdk2, cdk4, cdk6, anti-cyclin D, anti-cyclin E and anti-p21 antibodies were from Cell Signaling Technology (Boston, MA, USA). 96 AQueous One Solution Proliferation assay system was from Promega (Madison, WI, USA). Stock solution of VC-A (2 mM) was prepared in DMSO and all test concentrations were prepared by diluting stock solution in tissue culture medium.

Cell lines. MiaPaCa-2, Panc-1 and BxPC-3 PDA cell lines were obtained from the American Type Culture Collection (ATCC, Rockville, MD, USA). MiaPaCa-2 and Panc-1 cell lines were grown in DMEM tissue culture medium whereas BxPC-3 cells were cultured in RPMI-16 (Gibco BRL, Rockville, MD, USA) supplemented with $10 \%$ fetal bovine serum, $1 \%$ penicillin/ streptomycin, and $25 \mathrm{mM}$ HEPES buffer. Cells were incubated at $37^{\circ} \mathrm{C}$ in a humidified atmosphere consisting of $5 \% \mathrm{CO}_{2}$, $95 \%$ air and maintained by splitting cultures twice a week.

MTS assay. Tumor cells $\left(1 \times 10^{4}\right)$ in $100 \mu 1$ of tissue culture medium were seeded into each well of a 96-well plate. After 24-h incubation to allow cells to adhere, cells were treated with $\mathrm{VC}-\mathrm{A}$ at concentrations ranging from 0 to $0.625 \mu \mathrm{M}$. Cultures were incubated for additional $72 \mathrm{~h}$ and cell viability was then determined by the colorimetric MTS assay using CellTiter 96 AQueous One Solution Proliferation assay system from Promega (Madison), which measures the bioreduction of tetrazolium compound MTS in the presence of electroncoupling reagent phenazine methosulfate. The absorbance, which is directly proportional to the number of viable cells in the cultures, was measured at $490 \mathrm{~nm}$ using a microplate reader.

Cell cycle analysis. The distribution of cells in various cell cycle phases was analyzed by measuring cellular DNA content. Untreated (control) $\left(2 \times 10^{6}\right)$ or VC-A-treated cells were fixed in
$70 \%$ ethanol overnight at $4^{\circ} \mathrm{C}$. Cells were washed twice and resuspended in $0.8 \mathrm{ml}$ of PBS. To each tube, $100 \mu \mathrm{l}$ of DNAse free RNAse $(500 \mu \mathrm{g} / \mathrm{ml})$ and $100 \mu \mathrm{l}$ of propidium iodide $(500 \mu \mathrm{g} / \mathrm{ml})$ was added and tubes were incubated at room temperature in the dark for $30 \mathrm{~min}$. Cellular DNA content was determined by flow cytometry using Accuri C6 flow cytometer (Accuri Cytometers Inc. Ann Arbor, MI, USA).

Annexin V-FITC binding. Induction of apoptosis was assessed by the binding of Annexin V to phosphatidylserine, which is externalized to the outer leaflet of the plasma membrane early during apoptosis. Briefly, MiaPaCa-2 and BxPC-3 cells treated with VC-A $(0-0.625 \mu \mathrm{M})$ for $24 \mathrm{~h}$ were resuspended in the binding buffer provided in Annexin V-FITC apoptosis detection kit II (BD Biosciences, Pharmingen). Cells were mixed with $5 \mu \mathrm{l}$ of Annexin V-FITC reagent, $5 \mu \mathrm{l}$ of PI, and incubated for $30 \mathrm{~min}$ at room temperature in the dark. Stained cells were analyzed by flow cytometry.

Mitochondrial depolarization assay. Alteration in mitochondrial potential by VC-A was determined using mitochondrial potential sensor dye JC-1 (Molecular Probes, Invitrogen, San Diego, CA, USA). Briefly, $1 \times 10^{6}$ control (untreated) and VC-A- treated cells in $1 \mathrm{ml}$ culture medium were loaded with JC-1 $(10 \mu \mathrm{g} / \mathrm{ml})$ for $10 \mathrm{~min}$ at $22^{\circ} \mathrm{C}$ and analyzed by flow cytometry. In normal cells, dye is aggregated in mitochondria, fluoresces red, and is detected in the FL2 channel. In cells with altered mitochondrial potential, the dye fails to accumulate in the mitochondria, remains as monomers in the cytoplasm, fluoresces green, and is detected in the FL1 channel.

Western blotting. Cell lysates were prepared by detergent lysis [1\% Triton-X 100 (v/v), $10 \mathrm{mM}$ Tris- $\mathrm{HCl}(\mathrm{pH} 7.5), 5 \mathrm{mM}$ EDTA, $150 \mathrm{mM} \mathrm{NaCl}, 10 \%$ glycerol, $2 \mathrm{mM}$ sodium vanadate, $5 \mu \mathrm{g} / \mathrm{ml}$ leupeptin, $1 \mu \mathrm{g} / \mathrm{ml}$ aprotinin, $1 \mu \mathrm{g} / \mathrm{ml}$ pepstatin A and $10 \mu \mathrm{g} / \mathrm{ml} 4$-2-aminoethyl-benzenesulfinyl fluoride]. Lysates were clarified by centrifugation at $14,000 \mathrm{x} \mathrm{g}$ for $10 \mathrm{~min}$ at $4^{\circ} \mathrm{C}$, and protein concentrations were determined by Bradford assay. Samples $(50 \mu \mathrm{g})$ were boiled in an equal volume of sample buffer [ $20 \%$ glycerol, $4 \%$ SDS, $0.2 \%$ bromophenol blue, $125 \mathrm{mM}$ Tris- $\mathrm{HCl}$ (pH 7.5), and $640 \mathrm{mM}$ 2-mercaptoethanol] and separated on $10 \%$ SDS-polyacrilamide gels. Proteins resolved on the gels were transferred to nitrocellulose membranes. Membranes were blocked with $5 \%$ milk in $10 \mathrm{mM}$ Tris- $\mathrm{HCl}$ (pH 8.0), $150 \mathrm{mM} \mathrm{NaCl}$ with $0.05 \%$ Tween-20 (TPBS) and incubated with protein specific antibodies followed by HRP-conjugated secondary antibody. Immune complexes were visualized with enhanced chemiluminescence detection system from Amersham Corp. (Arlington Heights, IL, USA). The immunoblots were imaged and the density of protein bands was analyzed using Image/J software (imagej/nih.gov/ $\mathrm{ij} /$ download/). The protein band densities were normalized to the corresponding $\beta$-actin levels and presented as fraction of untreated control considered as 1.0 .

Statistical analysis. Data are presented as means \pm SD. The differences between control and treatment groups were analyzed using Student's t-test and differences with $\mathrm{p}<0.05$ were considered statistically significant. 
MiaPaCa-2

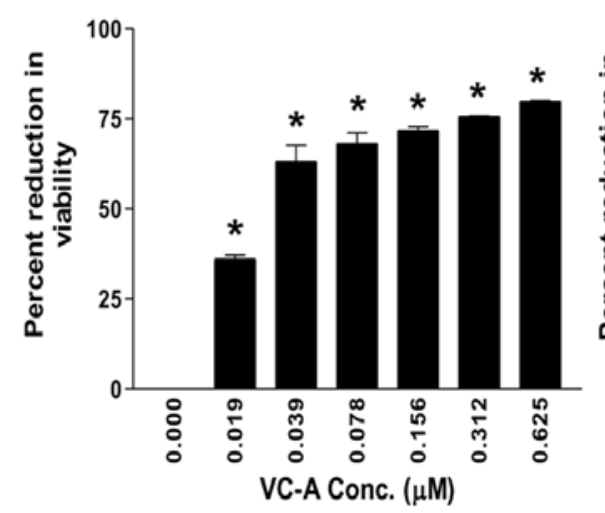

Panc-1

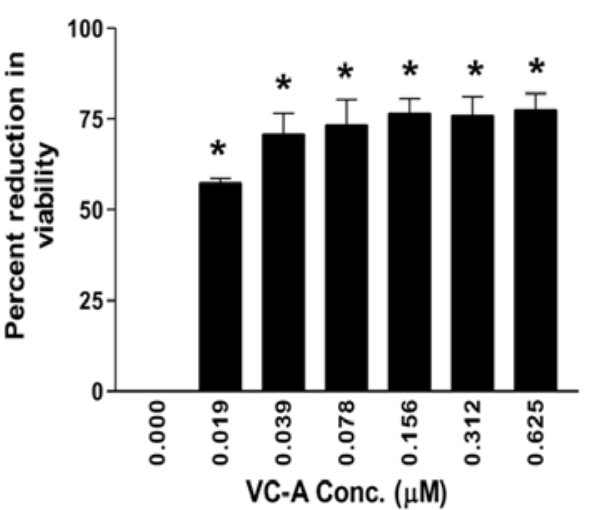

BxPC-3

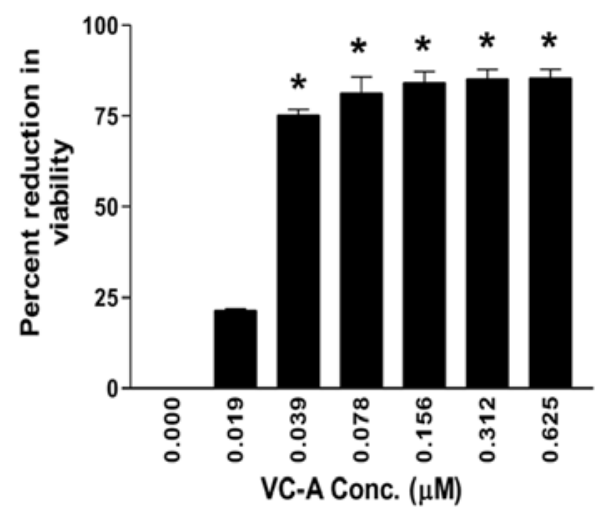

Figure 1. Verrucarin A inhibits proliferation of PDA cells. MiaPaCa-2, Panc-1 and BxPC-3 cells (1x104/well) were seeded in a 96-well plate for 24 h. Cells were then treated with VC-A at concentrations ranging from 0 to $0.625 \mu \mathrm{M}$ for $72 \mathrm{~h}$ in triplicate. Cell viability was measured by MTS assay using CellTiter AQueous assay system. ${ }^{*} \mathrm{p}<0.05$ compared to control cells. Experiment was repeated three times.

\section{Results}

$V C$-A inhibits proliferation and cell cycle progression in PDA cells. The effect of VC-A on proliferation of MiaPaCa-2, Panc-1 and BxPC-3 PDA cells was examined using the MTS assay. For this, cells were treated with VC-A at concentrations of $0-0.625 \mu \mathrm{M}$ for $72 \mathrm{~h}$ and the viability of cultures was determined. As shown in Fig. 1, significant reduction in viability was observed at the lowest concentration of $0.019 \mu \mathrm{M}$ VC-A (MiaPaCa-2 = 36 \pm 1.4 SD; Panc-1 = 57 \pm 1.8 SD, $\mathrm{p}<0.05$ ). BxPC-3 cultures also showed measurable reduction in viability at $0.019 \mu \mathrm{M}$ VC-A $(21 \pm 0.6 \mathrm{SD})$. In all three cell lines, reduction in viability significantly increased at $\mathrm{VC}-\mathrm{A}$ concentrations of 0.039-0.625 $\mu \mathrm{M}$ (MiaPaCa-2 $=63-80 \%$ reduction; Panc-1 $=57-78 \%$ reduction; $\mathrm{BxPC}-3=75-86 \%$ reduction, $\mathrm{p}<0.01$ ). These data demonstrated potent antiproliferative activity of VC-A against PDA cells.

In a previous report, VC-A was demonstrated to be 6-10-fold less cytotoxic to normal bone marrow cells compared to cancer cell lines (21). In addition, VC-A was also inactive or only weekly active against non-cancerous Vero cells derived from monkey kidney compared to cancer cell lines (12).

Verrucarin A induces cell cycle arrest and inhibits cell cyclerelated regulatory proteins in PDA cells. Since VC-A inhibited the proliferation of PDA cells we investigated its effect on cell cycle progression and cellular proteins that regulate cell division. For effect on cell cycle progression, MiaPaCa-2 and BxPC-3 cells were treated with VC-A $(0-0.04 \mu \mathrm{M})$ for $24 \mathrm{~h}$, stained with PI and cellular DNA content was analyzed by flow cytometry. Treatment with VC-A resulted in arrest of cells in the $\mathrm{S}$ cell cycle phase in both cell lines (Fig. 2A). In MiaPaCa-2 cells, the accumulation of cells in $\mathrm{S}$ phase was VC-A concentration-dependent (e.g., 17-27\% at 0-0.04 $\mu \mathrm{M}$ VC-A), whereas in BxPC-3 cells all of the S-phase arrest occurred at $0.04 \mu \mathrm{M}$ VC-A. To determine the effect of VC-A on cell cycle regulatory proteins, cell lysates of $\mathrm{MiaPaCa}-2$ and BxPC-3 cells treated with VC-A $(0.078-0.625 \mu \mathrm{M})$ for $24 \mathrm{~h}$ were analyzed for the levels of cyclin D1, cyclin E, cdk2, cdk4 and WAF1/21 (p21) by western blotting. As shown in Fig. 2B, treatment with $\mathrm{VC}-\mathrm{A}$ reduced the levels of these proteins mostly in a concentration-dependent manner. These data suggested that VC-A arrests PDA cells in S cell cycle phase by inhibiting cell cycle regulatory proteins.

$V C$ - $A$ induces apoptosis in PDA cells. Whether cell cycle arrest leads to the induction of apoptosis was investigated next. Induction of apoptosis was by analyzed by the binding of Annexin V-FITC to cells treated with VC-A. Thus, MiaPaCa-2 and BxPC-3 cells were treated with VC-A $(0.078-0.625 \mu \mathrm{M})$ for $24 \mathrm{~h}$ and binding of Annexin V-FITC was determined by flow cytometry. As shown in Fig. 3A, only a small percentage of untreated MiaPaCa- 2 and $\mathrm{BxPC}-3$ cells bound Annexin V-FITC $(<5 \%)$. The percentage of Annexin V-FITC binding $\mathrm{MiaPaCa}-2$ increased from $51 \%$ at $0.078 \mu \mathrm{M}$ to $57 \%$ at $0.625 \mathrm{VC}-\mathrm{A}(\mathrm{p}<0.01)$. On the other hand, the percentage of Annexin V-FITC binding BxPC-3 cells increased in a dosedependent manner, e.g., 24, 31, 3 and $43 \%$ at $0.078,0.15,0.325$ and $0.625 \mu \mathrm{M}$ VC-A.

The induction of apoptosis by VC-A was confirmed by the cleavage of PARP-1 and procaspases. Tumor cells were treated with VC-A as described above and the cleavage of PARP-1 and procaspases was analyzed by western blotting. As shown in Fig. 3B, treatment with VC-A induced the cleavage of native PARP-1 (110-kDa fragment) as identified by the emergence of an 89-kDa cleaved PARP-1 fragment in both cell lines. Treatment with VC-A also induced the processing of procaspases-3,-8 and -9 as determined from a decrease in native proteins (procaspases-3 and -8) or the emergence of the cleaved fragments (procaspase-9) (Fig. 3C). However, the effect of VC-A on the activity of these caspases was not determined. Together, increase in Annexin V-FITC-binding and the cleavage of PARP-1 and processing of procaspases-3, -8 and -9 demonstrated induction of apoptosis in PDA cells by VC-A.

$V C$-A induces mitochondrial depolarization and release of cytochrome $c$. Whether mitochondrial pathway of apoptosis was involved in the apoptotic cell death of PDA cells by VC-A was examined next. As a measure of mitochondrial involvement in induction of apoptosis by VC-A, we evaluated 
A
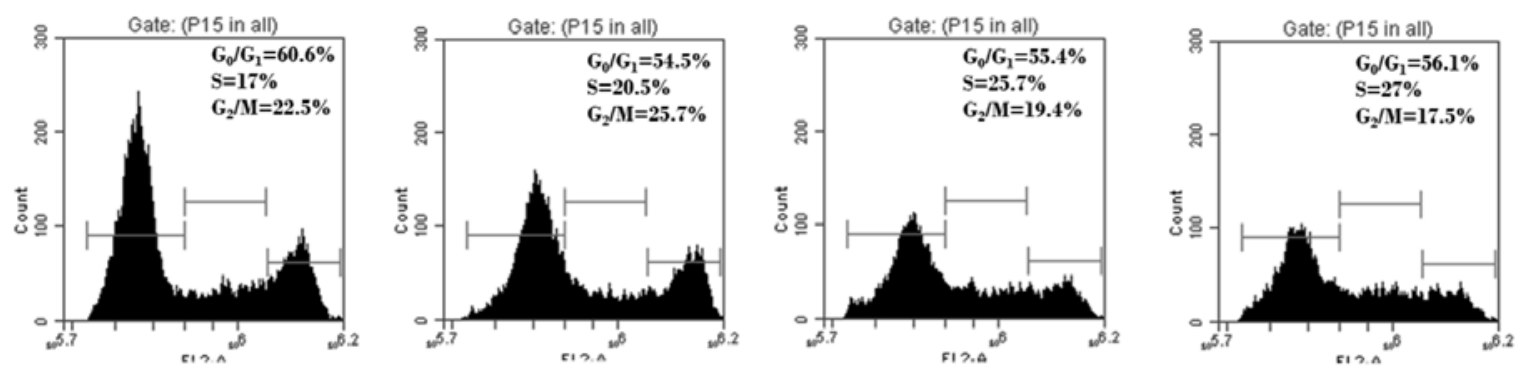

$\mathrm{MiaPaCa}-2$

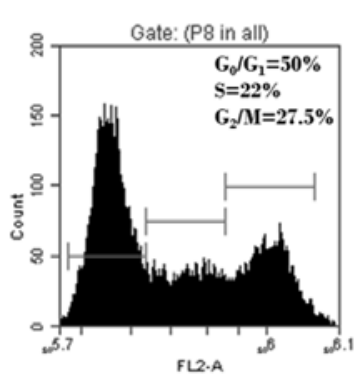

0.00

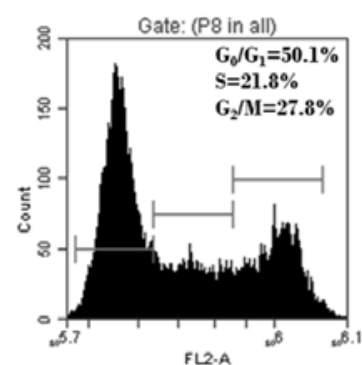

0.01

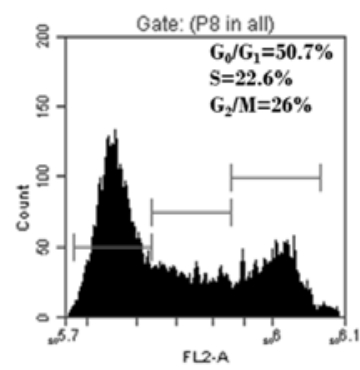

0.02

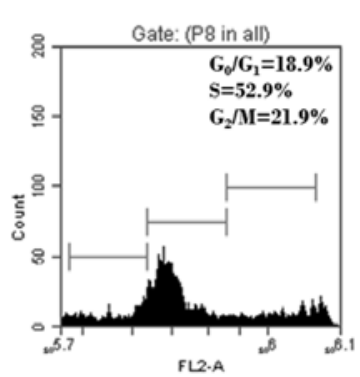

0.04

Concentration of VC-A $(\mu \mathrm{M})$

B

MiaPaCa-2

$\begin{array}{lllll}1 & 0.5 & 0.2 & 0.0 & 0.05\end{array}$

Cyclin D1

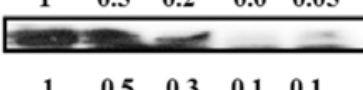

Cyclin E

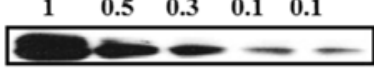

cdk2

cdk4

p21

及-actin $\begin{array}{lllll}1 & 0.3 & 0.3 & 0.3 & 0.3\end{array}$
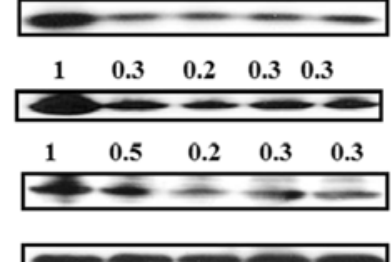

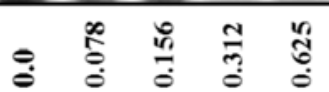

VC-A Conc. ( $\mu \mathrm{M})$
BxPC-3

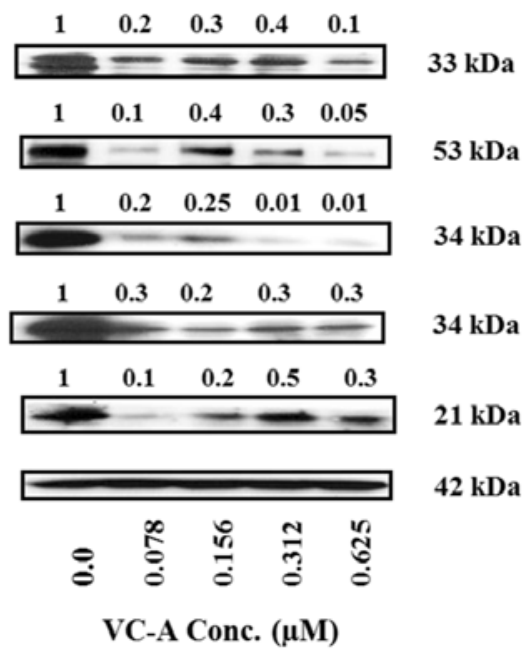

Figure 2. Effect of verrucarin A on cell cycle progression and cell cycle regulatory proteins. (A) Effect on cell cycle progression. MiaPaCa-2 and BxPC-3 cells were treated with VC-A $(0-0.08 \mu \mathrm{M})$ for $48 \mathrm{~h}$. Cells were fixed in $70 \%$ ethanol and then stained with ethidium bromide. The cell cycle distribution was determined by analyzing cellular DNA content by flow cytometry using Accuri 6 flow cytometer (Becton-Dickinson). (B) Effect of cell cycle-regulatory proteins. MiaPaCa-2 and BxPC-3 cells were treated with VC-A $(0-0.625 \mu \mathrm{M})$ for $24 \mathrm{~h}$ and cell lysates were analyzed for levels of cyclin D1, cyclin E, cdk2, cdk4 and p21 by western blotting. The densitometry analysis of immunoblots was performed using Image/J software and normalized to the corresponding $\beta$-actin values. Values above blots represent change in protein expression compared to untreated control considered as 1.0. Experiment was repeated two times.

mitochondrial depolarization in cells treated with $\mathrm{VC}-\mathrm{A}$. Thus, MiaPaCa-2 and BxPC-3 cells were treated with VC-A $(0-0.625 \mu \mathrm{M})$ for $24 \mathrm{~h}$ and then loaded with mitochondrialpotential sensor probe JC-1 and fluorescence emission was analyzed by flow cytometry. There was significant change in the mitochondrial potential in both cell lines after treatment with VC-A. As shown in Fig. 4A, the percentage of MiaPaCa-2 cells with green fluorescence significantly increased from $3 \%$ at $0 \mu \mathrm{M}$ VC-A to $29,42,44$ and $48 \%$ at $0.078-0.625 \mu \mathrm{M}$ VC-A $(\mathrm{p}<0.01)$. VC-A also showed strong mitochondrial depolar- izing effect on BxPC-3 cells (e.g., 5, 39, 53, 66 and $62 \%$ of cells with green fluorescence at $0,0.078,0.156,0.312$ and $0.625 \mu \mathrm{M}$ VC-A, $\mathrm{p}<0.01)$.

We also analyzed the effect of VC-A on the release of cytochrome $c$ from mitochondria. Western blot analysis of mitochondrial fraction of MiaPaCa-2 and $\mathrm{BxPC}-3$ cells treated with VC-A $(0-0.625 \mu \mathrm{M})$ demonstrated the release of cytochrome $c$ in both cell lines in a concentration-dependent manner (Fig. 4B). Taken together, the loss of mitochondrial membrane potential and release of cytochrome $c$ from 


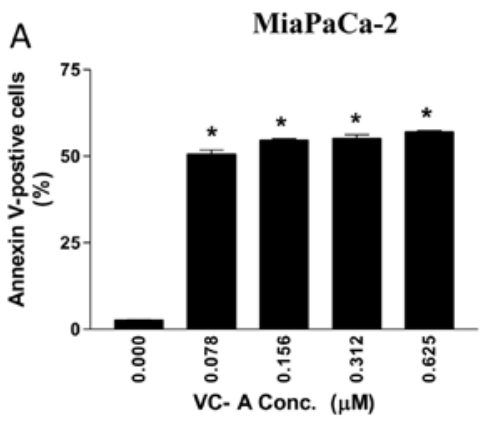

BxPC-3

B
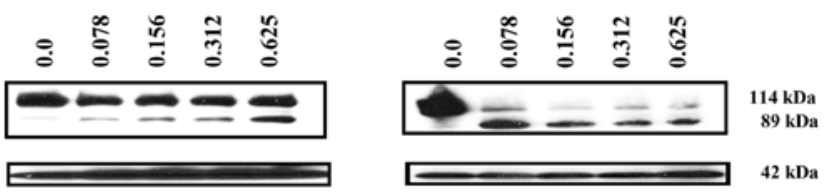

VC-A Conc. $(\mu \mathrm{M})$

VC-A Conc. $(\mu \mathrm{M})$

C

Pro-caspase-3

$\begin{array}{lllll}1 & 0.5 & 0.4 & 0.6 & 0.2\end{array}$

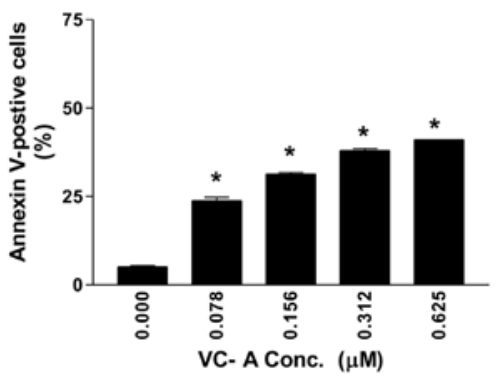

Pro-caspase-9
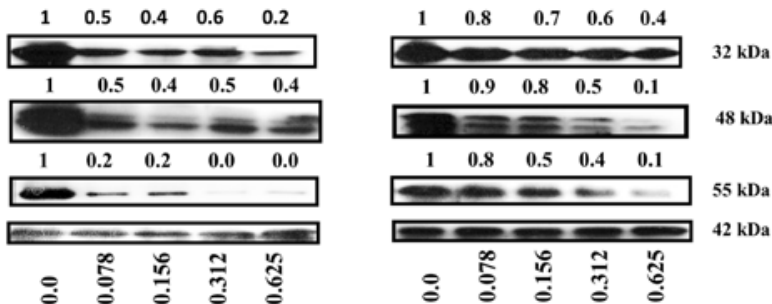

Pro-caspase-8

$\beta$-actin

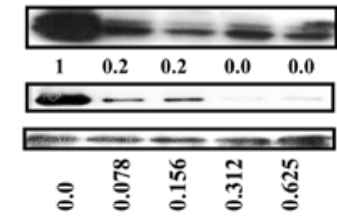

VC-A Conc. $(\mu \mathrm{M})$

VC-A Conc. $(\mu \mathrm{M})$

Figure 3. Verrucarin A induces apoptosis in PDA cells. (A) Annexin V-FITC binding. MiaPaCa-2 and BxPC-3 cells were treated with VC-A (0-0.625 $\mu$ M) for $24 \mathrm{~h}$. Cells were then reacted with $5 \mu \mathrm{l}$ of Annexin V-FITC reagent and $5 \mu \mathrm{l}$ of PI for $30 \mathrm{~min}$ at room temperature. Annexin V-FITC-binding was assessed by flow cytometry. Results are presented as percentage of Annexin V-FITC-positive cells \pm SD of three separate experiments. "p $<0.05$ compared to control cells. (B) Cleavage of PARP-1. MiaPaCa-2 and BxPC-3 cells were treated with VC-A as in (A) and cell lysates were analyzed for the cleavage of native PARP-1 by western blotting. Immunoblots show cleaved PARP-1 protein bands $(89 \mathrm{kDa})$. (C) Cleavage of procaspases. Tumor cells were treated with VC-A as in (A) and cell lysates were analyzed by immunoblotting for processing of procaspases-3, -8 and -9 . The densitometry analysis of immunoblots in (B) and (C) was performed using Image/J software and normalized to the corresponding $\beta$-actin values. Values above blots represent change in protein expression compared to untreated control considered as 1.0. Similar results were obtained in two independent experiments.

A

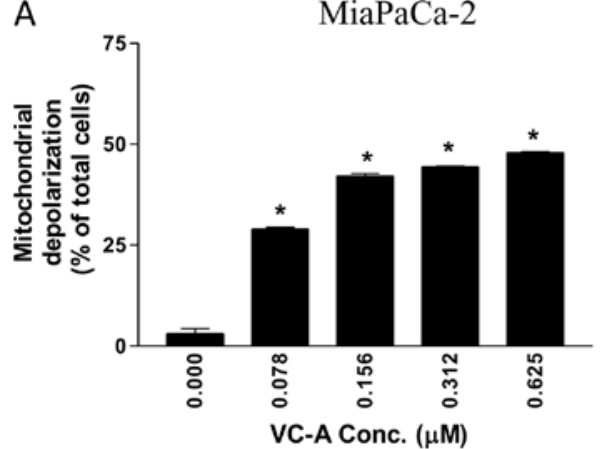

B

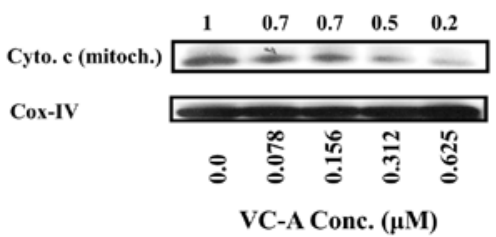

BxPC-3
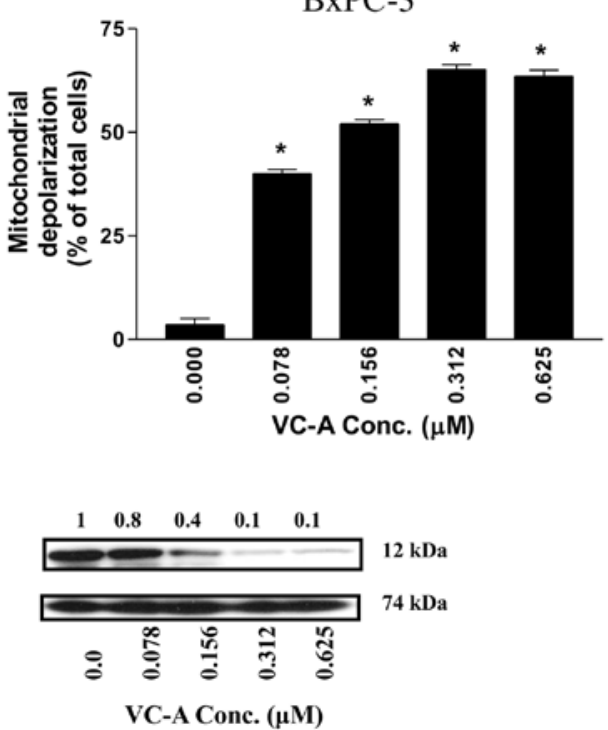

Figure 4. VC-A induces mitochondrial depolarization and release of cytochrome $c$. (A) Mitochondrial depolirazation. MiaPaCa-2 and BxPC-3 cells with VC-A $(0-0.625 \mu \mathrm{M}$ for $24 \mathrm{~h}$. Cells were then loaded with mitochondrial sensor dye JC-1 for $10 \mathrm{~min}$ and analyzed by flow cytometry. Data shown are percentage of cells with mitochondrial depolarization \pm SD. Similar results were obtained in two separate experiments. ${ }^{*} \mathrm{p}<0.05$ compared to control cells. (B) Cytochrome $c$ release. For cytochrome $c$ release from mitochondria, mitochondrial fractions were prepared from control and treated cells using ApoAlert Cell Fractionation kit (Clontech, Laboratories Inc., CA, USA) and cytochrome $c$ analyzed by western blotting. The densitometry analysis of immunoblots was performed using Image/J software and normalized to the corresponding Cox-IV values. Values above blots represent change in protein expression compared to untreated control considered as 1.0. Similar results were obtained in two independent experiments in (A) and (B). 

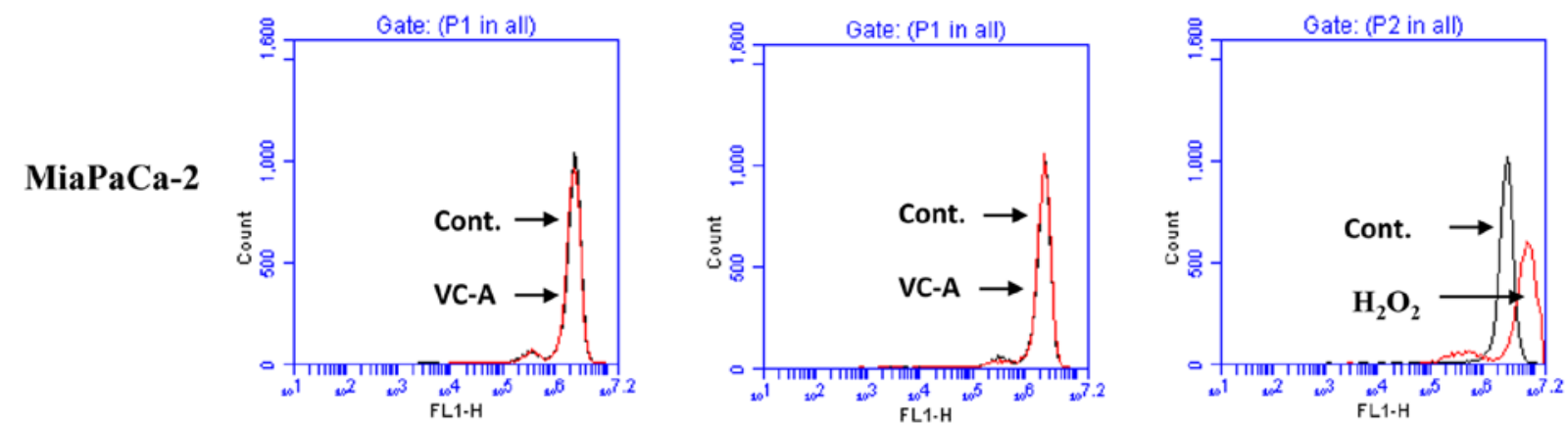

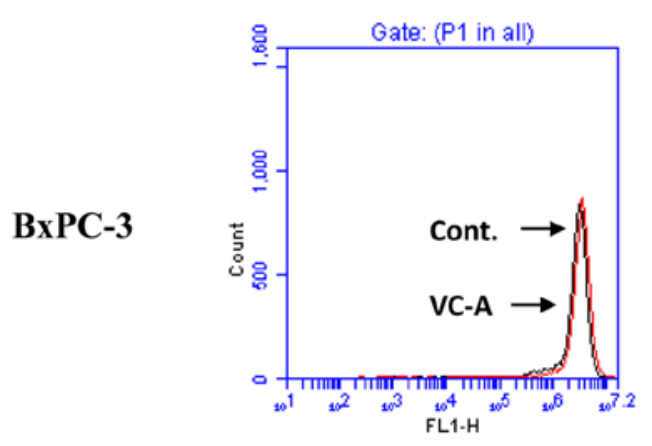

$1.25 \mu \mathrm{M} \mathrm{VC-A}$

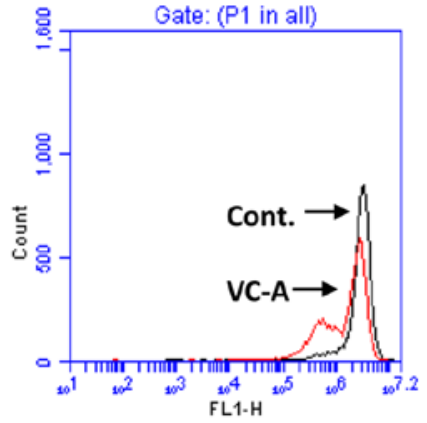

$2.5 \mu \mathrm{M}$ VC-A

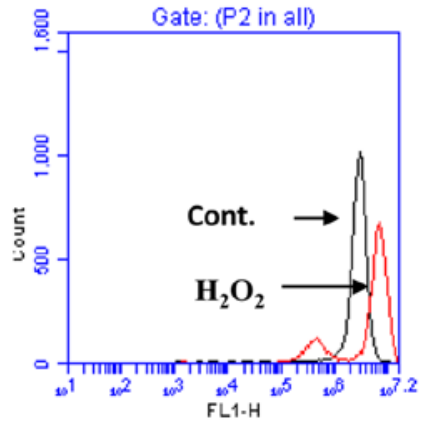

$100 \mu \mathrm{M} \mathrm{H}_{2} \mathrm{O}_{2}$

Figure 5. VC-A does not induce ROS generation in PDA cells. Subconfluent cultures of MiaPaCa-2 and BxPC-3 cells were treated with VC-A (1.25 or $2.5 \mu \mathrm{M})$ or $\mathrm{H}_{2} \mathrm{O}_{2}(100 \mu \mathrm{M})$ for $2 \mathrm{~h}$. Cells were then reacted with $5 \mu \mathrm{M} \mathrm{H}_{2}$ DCFDA for $30 \mathrm{~min}$ at $37^{\circ} \mathrm{C}$ and DCF fluorescence was measured by flow cytometry. In contrast to PDA cells treated with $\mathrm{H}_{2} \mathrm{O}_{2}$ (positive control), none to barely detectable DCF fluorescence was detected in cells treated with VC-A. Experiment was repeated two times.

mitochondria indicated that mitochondrial damage plays a significant role in apoptotic cell death of PDA cells by VC-A.

$V C$-A does not induce ROS generation. Since generation of free radicals is part of the mechanism by which most chemotherapeutic agents induce apoptosis in cancer cells we evaluated the generation of ROS by VC-A in PDA cells. This was accomplished by detecting $\mathrm{H}_{2} \mathrm{O}_{2}$ production by flow cytometry using $\mathrm{H}_{2}$ DCFDA fluorescent probe. As shown in Fig. 5, whereas treatment of MiaPaCa-2 and BxPC-3 cells with $\mathrm{H}_{2} \mathrm{O}_{2}$ resulted in production of hydroxyl radicals (positive control) treatment with VC-A at 1.25 and $2.5 \mu \mathrm{M}$ for $2 \mathrm{~h}$ failed to induce the generation of these free radicals. Further, no ROS was detected either when cells were treated with VC-A for 1 or $4 \mathrm{~h}$ (not shown).

VC-A downregulates Bcl-2 and IAP family proteins. To further characterize apoptotic response of PDA cells to VC-A, the effect of $\mathrm{VC}-\mathrm{A}$ on proteins belonging to the $\mathrm{Bcl}-2$ and IAP families of proteins that regulate apoptosis positively and negatively was determined. For this, cell lysates prepared from MiaPaCa-2 and BxPC-3 cells treated or not with VC-A $(0.079-0.625 \mu \mathrm{M})$ for $24 \mathrm{~h}$ were analyzed for Bcl-2, Bcl-xL, Bax, p-Bad, survivin and c-IAP-2 by western blotting. As shown in Fig. 6, treatment with VC-A significantly to completely inhibited the levels of antiapoptotic Bcl-2 and Bcl-xL in both cell lines. Proapoptotic Bax was unaffected in $\mathrm{MiaPaCa}-2$ cells but was reduced in BxPC-3 cells. Even though Bax levels were somewhat reduced in BxPC-3 cells but the Bax/Bcl-2 ratio was increased 2-3-fold in both cell lines treated with VC-A (e.g., MiaPaCa-2: 2.7-, 2.7-, 3.2- and 2.7-fold; BxPC-3: 3-, 2-, 3- and 2-fold at 0.079, 0.158, 0.312 and $0.625 \mu \mathrm{M}$, respectively). Proapototic p-Bad was also reduced but still detectable in both cell lines. Similarly, antiapoptotic survivin (IAP family member) was significantly reduced in both cell lines $(60-80 \%)$. On the other hand, while cIAP-2 was markedly reduced at 0.312 and $0.625 \mu \mathrm{M}$ VC-A in MiaPaCa- 2 cells, effect on c-IAP-2 expression in BxPC-3 cells was minimal. Overall, these data suggested that inhibition of antiapoptotic proteins plays a role in induction of apoptosis by VC-A in PDA cells.

$V C$ - $A$ inhibits Akt, mTOR and $N F-\kappa B$ signaling proteins and their downstream mediators. Akt/NF- $\mathrm{BB} / \mathrm{mTOR}$ is a major antiapoptotic (prosurvival) signaling pathway that confers survival advantage in cancer cells including PDA cells. We investigated whether induction of apoptosis in prostate cancer cells by VC-A involved the inhibition of Akt, mTOR and $\mathrm{NF}-\kappa \mathrm{B}$ and their downstream mediators. Thus, cell lysates prepared from MiaPaCa-2 and BxPC-3 cells treated or not with VC-A $(0-0.625 \mu \mathrm{M})$ for $24 \mathrm{~h}$ were analyzed for $\mathrm{p}$-Akt, mTOR and NF-KB and their effectors by western blotting. Treatment with VC-A markedly reduced the levels of $\mathrm{p}-\mathrm{Akt}$, p-mTOR and NF-KB (p65) in both cell lines (Fig. 7). Further analysis of cell lysates showed that VC-A also inhibited the major downstream intermediary targets of Akt, mTOR and NF- $\kappa$ B. For instance, VC-A inhibited the expression of p-Foxo- $3 \alpha$, the downstream target of activated Akt involved in cell proliferation and apoptosis. Similarly, the levels of mTOR 
MiaPaCa-2

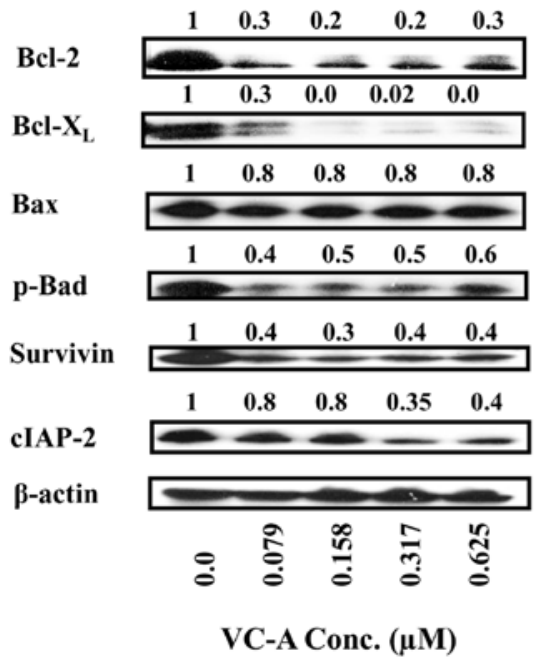

BxPC-3

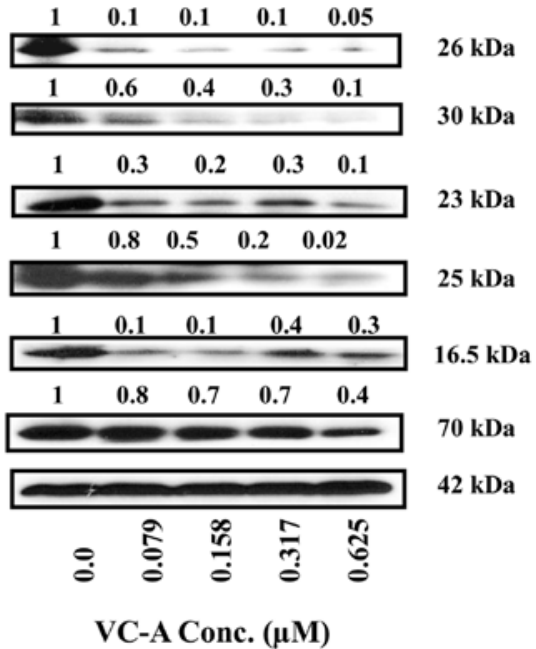

Figure 6. Effect of VC-A on apoptosis-regulating proteins. MiaPaCa-2 and BxPC-3 cells were treated with VC-A at $0-0.065 \mu \mathrm{M}$ for $24 \mathrm{~h}$ and cell lysates were analyzed for Bcl-2, Bcl-xL, Bax, p-Bad, survivin and c-IAP-2 by western blotting. The densitometry analysis of immunoblots was performed using Image/J software and normalized to the corresponding $\beta$-actin values. Values above blots represent change in protein expression compared to untreated control considered as 1.0. Experiment was repeated two times.

MiaPaCa-2

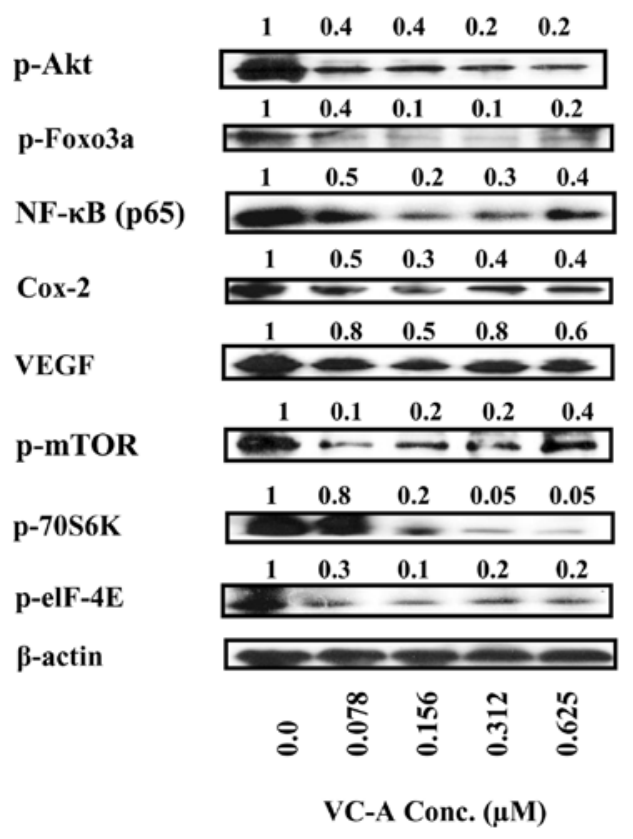

\section{BxPC-3}

\begin{tabular}{|c|c|c|c|c|c|}
\hline 1 & 0.5 & 0.3 & 0.3 & 0.2 & \\
\hline & 5 & $\equiv$ & $=$ & $\longrightarrow$ & $60 \mathrm{kDa}$ \\
\hline 1 & 0.4 & 0.3 & 0.3 & 0.2 & \\
\hline & & & & $\Rightarrow$ & 97 kDa \\
\hline 1 & 0.5 & 0.1 & 0.05 & 0.0 & \\
\hline & - & - & 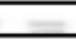 & 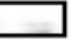 & 65 kDa \\
\hline 1 & 0.3 & 0.3 & 0.4 & 0.3 & \\
\hline$\pi$ & $\equiv$ & 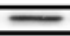 & $=$ & $=$ & 74 kDa \\
\hline 1 & 0.1 & 0.1 & 0.2 & 0.1 & \\
\hline 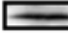 & & $=$ & $=$ & $\Longrightarrow$ & $21 \mathrm{kDa}$ \\
\hline 1 & 0.8 & 0.7 & 0.1 & 0.2 & \\
\hline$\Longrightarrow$ & $=$ & $=$ & $=$ & - & $289 \mathrm{kDa}$ \\
\hline 1 & 0.3 & 0.3 & 0.3 & 0.2 & \\
\hline 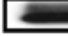 & - & $=$ & $=$ & $=$ & $60 \mathrm{kDa}$ \\
\hline 1 & 0.0 & 0.0 & 0.1 & 0.1 & \\
\hline- & & & 3 & 4 & $25 \mathrm{kDa}$ \\
\hline & & & & $=$ & 42 kDa \\
\hline$\stackrel{\ominus}{0}$ & $\stackrel{\infty}{\stackrel{\infty}{0}}$ & $\frac{\circ}{0}$ & $\stackrel{\overbrace{}}{\frac{\pi}{6}}$ & ఝ్ర & \\
\hline & VC-A & Con & c. $(\mu \mathrm{M}$ & & \\
\hline
\end{tabular}

Figure 7. VC-A inhibits prosurvival p-Akt, NF- $\mathrm{BB}$ and p-mTOR. MiaPaCa-2 and BxPC-3 cells were treated with VC-A at $0-0.625 \mu \mathrm{M}$ for $24 \mathrm{~h}$ and cell lysates were analyzed for p-Akt, NF-kB, p-mTOR and their downstream mediators (p-Foxo3 $\alpha$, Cox-2, VEGF, p-70S6, and p-eIF-4e, etc.) or $\beta$-actin (loading control) by western blotting. The densitometry analysis of immunoblots was performed using Image/J software and normalized to the corresponding $\beta$-actin values. Values above blots represent change in protein expression compared to untreated control considered as 1.0. Experiment was repeated two times.

effectors such as p-S6K1 (p-70S6 kinase) and p-eIF-4e were markedly decreased after treatment with VC-A. In addition, the levels of angiogenesis related Cox-2 and VEGF, which are transcriptionally regulated by NF- $\mathrm{kB}$ were also markedly reduced. Collectively, these data suggested that the inhibition of p-Akt, p-mTOR, NF- $\kappa \mathrm{B}$ and their downstream mediators might be necessary for induction of apoptosis in PDA tumors by VC-A.

\section{Discussion}

There is an urgent need for effective and safe novel agents with defined therapeutic targets for treating pancreatic cancer. Natural products have long been recognized as a rich source of chemical diversity and compounds with a wide spectrum of anticancer activities $(22,23)$. Indeed, isolation and identification of bioactive components from medicinal plants have 
led to the synthesis of potent anticancer drugs, including Vinca alkaloids, taxol, camptothecan, etoposide and retinoids. Verrucarin A (VC-A) is a macrocyclic trichothecene mycotoxin that has shown strong antiproliferative and proapoptotic activity in breast cancer cells $(17,18)$, providing some insights into the mode of action of VC-A. However, the antitumor activity or the mechanism of action of VC-A in pancreatic cancer cells has not been investigated. Thus, this study was undertaken to investigate the antitumor activity and to identify targets of VC-A in PDA cells. VC-A inhibited the proliferation of three PDA cell lines (e.g., MiaCa-2, Panc1 and BxPC-3) at very low concentrations. The antiproliferative effect of $\mathrm{VC}-\mathrm{A}$ was attributed to the inhibition of cell cycle progression in $\mathrm{S}$ phase. This finding however differs from a previous report in which VC-A was shown to arrest cells in G0/G1 phase (17). Furthermore, cell cycle arrest by VC-A was associated with the inhibition of cyclin D1, cyclin E, cdk2, cdk-4 and cdk inhibitor p21. Cyclin D and E in conjunction with cdk2, cdk4 and cdk6 regulate cell cycle progression through G1 and $\mathrm{S}$ phases. The inhibition of cyclin $\mathrm{E}$ and cdk2 suggests that inhibition of these proteins would result in decreased formation of cyclin E-cdk2 complexes and therefore accumulation of cells in $\mathrm{S}$ phase. The cip/kip family member $\mathrm{p} 21$ halts cell cycle progression by inhibiting cyclin-cdk complexes. VC-A only partially reduced p21 in PDA cells, perhaps not enough to hamper the activity of cyclin E-cdk 2 complexes.

The inability to induce apoptosis has been implicated in cancer development and resistance to cancer therapies (24). On the other hand, promotion of apoptosis in cancer cells could potentially lead to tumor regression and improved prognosis (25). The inhibition of cell proliferation by anticancer agents normally forces tumor cells to undergo apoptosis. Indeed, VC-A induced apoptosis in PDA cells as demonstrated by the increased binding of Annexin V and cleavage of PARP-1 and procaspases-3, -8 and -9 . These results corroborate the findings of another study that also reported cell cycle arrest and induction of apoptosis in breast cancer cells by VC-A (17). The cleavage of procaspases- 8 and -9 suggested that VC-A induces both the extrinsic and intrinsic pathways of apoptosis. However, additional studies, such as an increase in the expression of death receptors DR4 and DR5, are required to confirm the activation of extrinsic pathway of apoptosis by VC-A. Mitochondria plays a critical role in the intrinsic pathway of apoptosis. Breakdown in mitochondrial integrity and the release of cytochrome $c$ and other apoptogenic mediators are the best indicators of apoptotic cell death via the intrinsic pathway of apoptosis. VC-A induced mitochondrial depolarization and release of cytochrome $c$ indicating the involvement of mitochondrial or intrinsic pathway of apoptosis in death of PDA cells by VC-A.

The generation of free radicals facilitates cancer cell death by most chemotherapeutic agents and ionizing radiation $(26,27)$. Our findings demonstrated that production of hydrogen peroxide is not involved in death of PDA cells by VC-A. This finding contradicts a previous report in which ROS was shown to be involved in killing of breast cancer by VC-A (17). Our results, however, do not rule out participation of other reactive oxygen species such as superoxide anion in $\mathrm{VC}-\mathrm{A}$ induced death of PDA cells.

Apoptosis is regulated by members of the Bcl-2 family of proteins that includes both pro- and anti-apoptotic molecules
$(28,29)$. Members of the IAP family are also potent inhibitors of apoptosis (30). Bcl-2 and Bcl-xL are two major antiapoptotic Bcl-2 family members that reside in the mitochondrial membrane and inhibit apoptosis by preventing the activation of inner mitochondrial permeability transition pore and release of proapoptogenic mitochondrial contents including cytochrome $c$ (29). VC-A inhibited Bcl-2 and Bcl-xL in PDA cells. Bax and p-Bad which counteract antiapoptotic Bcl-2 and Bcl-xL were either not affected or only partially reduced by VC-A. Since both anti- and proapoptotic Bcl-2 family members were inhibited or reduced the exact nature of the interplay between antiapoptotic and proapoptotic members of Bcl-2 family in induction of apoptosis in PDA cells by VC-A remains unresolved. On the contrary, however, increase in Bax:Bcl-2 ratio after treatment with VC-A suggests that VC-A may exert proapoptotic effect by displacing Bcl-2 from mitochondria through Bax.

Prosurvival phosphatidylinositol-3 kinase/Akt/NF-KB/ mTOR (PI3K/Akt/NF-KB/mTOR) is a major signaling axis which controls cell proliferation, survival, apoptosis, and malignant transformation (31). PI3K/Akt signaling is frequently activated in a variety of malignancies (32). p-Akt promotes cell growth and survival by inactivating downstream substrates such as Bad, procaspase-9, and Forkhead transcription factors $(33,34)$. Antiapoptotic NF- $\mathrm{NB}$ and progrowth mTOR signaling pathways are downstream targets of activated Akt. NF- $\kappa \mathrm{B}$ family of transcription factors controls the expression of genes involved in immune and inflammatory responses, cell proliferation, oncogenesis, angiogenesis, and several Bcl-2 family members (35). NF- $\kappa \mathrm{B}$ also plays a critical role in resistance of cancer cells to anticancer therapies by protecting them from apoptosis. mTOR, a 290-kDa serine-threonine kinase, which controls cell growth, survival and division is activated in a variety of human tumors (36). Our results demonstrated that Akt, NF- $\kappa \mathrm{B}$ and mTOR are constitutively active in PDA cells and their expression was inhibited by VC-A. VC-A also reduced the expression of several downstream effectors of Akt, $\mathrm{NF}-\kappa \mathrm{B}$ and mTOR that regulate cell proliferation, cell cycle, apoptosis and ribogenesis. These findings suggest that the inhibition of Akt/NF-KB/mTOR signal transduction pathway plays a critical role in induction of apoptosis in pancreatic cancer cells by VC-A.

Collectively, results of this study indicate that $\mathrm{VC}-\mathrm{A}$ is a promising agent worthy of further development for the treatment of pancreatic cancer.

\section{Acknowledgements}

This study was supported by an institutional grant A10176 to S.C.G.

\section{References}

1. National Cancer Institute: Pancreatic Cancer-National Cancer Institute, U.S. National Institutes of Health. Cancer. www.cancer. gov/cancertopics/types/pancreatic. Accessed 06-04-2010.

2. Maitra A and Hruban RH: Pancreatic cancer. Annu Rev Pathol 3: 157-188, 2008.

3. Li D, Xie K, Wolff R and Abbruzzese JL: Pancreatic cancer. Lancet 363: 1049-1057, 2004.

4. Mulcahy MF, Wahl AO and Small W Jr: The current status of combined radiotherapy and chemotherapy for locally advanced or resected pancreas cancer. J Natl Compr Canc Netw 3: 637-642, 2005. 
5. Pino SM, Xiong HQ, McConkey D and Abbruzzese JL: Novel therapies for pancreatic adenocarcinoma. Curr Oncol Rep 6: 199-206, 2004.

6. Vaccaro V, Sperduti I and Milella M: FOLFIRINOX versus gemcitabine for metastatic pancreatic cancer. N Engl J Med 365: 768-769, author reply 769, 2011.

7. Pestka JJ, Yike I, Dearborn DG, Ward MD and Harkema JR Stachybotrys chartarum, trichothecene mycotoxins, and damp building-related illness: New insights into a public health enigma. Toxicol Sci 104: 4-26, 2008.

8. Hossain MA, Ahmed MS and Ghannoum MA: Attributes of Stachybotrys chartarum and its association with human disease J Allergy Clin Immunol 113: 200-208, quiz 209, 2004.

9. Kilburn KH: Role of molds and mycotoxins in being sick in buildings: Neurobehavioral and pulmonary impairment. Adv Appl Microbiol 55: 339-359, 2004.

10. Hardin BD, Kelman BJ and Saxon A: Adverse human health effects associated with molds in the indoor environment. J Occup Environ Med 45: 470-478, 2003.

11. Leatherman DL and Middlebrook JL: Effect of emetine on T-2 toxin-induced inhibition of protein synthesis in mammalian cells. J Pharmacol Exp Ther 266: 741-748, 1993.

12. Ge HM, Jiao RH, Zhang YF, Zhang J, Wang YR and Tan RX: Cytotoxicity and phytotoxicity of trichothecene macrolides from Myrothecium gramminum. Planta Med 75: 227-229, 2009.

13. Abbas HK, Johnson BB, Shier WT, Tak H, Jarvis BB and Boyette CD: Phytotoxicity and mammalian cytotoxicity of macrocyclic trichothecene mycotoxins from Myrothecium verrucaria. Phytochemistry 59: 309-313, 2002.

14. Shifrin VI and Anderson P: Trichothecene mycotoxins trigger a ribotoxic stress response that activates c-Jun N-terminal kinase and p38 mitogen-activated protein kinase and induces apoptosis J Biol Chem 274: 13985-13992, 1999.

15. Chung YJ, Jarvis B and Pestka J: Modulation of lipopolysaccharide-induced proinflammatory cytokine production by satratoxins and other macrocyclic trichothecenes in the murine macrophage. J Toxicol Environ Health A 66: 379-391, 2003.

16. Hughes BJ, Taylor MJ and Sharma RP: Effects of verrucarin A and roridin A, macrocyclic trichothecene mycotoxins, on the murine immune system. Immunopharmacology 16: 79-87, 1988

17. Palanivel K, Kanimozhi V and Kadalmani B: Verrucarin A alters cell-cycle regulatory proteins and induces apoptosis through reactive oxygen species-dependent p38MAPK activation in the human breast cancer cell line MCF-7. Tumour Biol 35 10159-10167, 2014.

18. Palanivel K, Kanimozhi V, Kadalmani B and Akbarsha MA Verrucarin A induces apoptosis through ROS-mediated EGFR/ MAPK/Akt signaling pathways in MDA-MB-231 breast cancer cells. J Cell Biochem 115: 2022-2032, 2014.

19. Woldemichael GM, Turbyville TJ, Vasselli JR, Linehan WM and McMahon JB: Lack of a functional VHL gene product sensitizes renal cell carcinoma cells to the apoptotic effects of the protein synthesis inhibitor verrucarin A. Neoplasia 14: 771-777, 2012.
20. Yang GH, Jarvis BB, Chung YJ and Pestka JJ: Apoptosis induction by the satratoxins and other trichothecene mycotoxins: Relationship to ERK, p38 MAPK, and SAPK/JNK activation. Toxicol Appl Pharmacol 164: 149-160, 2000.

21. Amagata T, Rath C, Rigot JF, Tarlov N, Tenney K, Valeriote FA and Crews P: Structures and cytotoxic properties of trichoverroids and their macrolide analogues produced by saltwater culture of Myrothecium verrucaria. J Med Chem 46: 4342-4350, 2003.

22. Chin YW, Balunas MJ, Chai HB and Kinghorn AD: Drug discovery from natural sources. AAPS J 8: E239-E253, 2006.

23. Itokawa H, Morris-Natschke SL, Akiyama T and Lee KH: Plantderived natural product research aimed at new drug discovery. J Nat Med 62: 263-280, 2008

24. Kerr JF, Winterford CM and Harmon BV: Apoptosis. Its significance in cancer and cancer therapy. Cancer 73: 2013-2026, 1994.

25. Cusack JC Jr: Overcoming antiapoptotic responses to promote chemosensitivity in metastatic colorectal cancer to the liver. Ann Surg Oncol 10: 852-862, 2003.

26. Ramanathan B, Jan KY, Chen $\mathrm{CH}$, Hour TC, Yu HJ and Pu YS: Resistance to paclitaxel is proportional to cellular total antioxidant capacity. Cancer Res 65: 8455-8460, 2005.

27. Sun Y and Rigas B: The thioredoxin system mediates redoxinduced cell death in human colon cancer cells: Implications for the mechanism of action of anticancer agents. Cancer Res 68: 8269-8277, 2008.

28. Chao DT and Korsmeyer SJ: BCL-2 family: Regulators of cell death. Annu Rev Immunol 16: 395-419, 1998.

29. Green DR and Reed JC: Mitochondria and apoptosis. Science 281: 1309-1312, 1998.

30. Deveraux QL and Reed JC: IAP family proteins - suppressors of apoptosis. Genes Dev 13: 239-252, 1999.

31. Vivanco I and Sawyers CL: The phosphatidylinositol 3-kinase AKT pathway in human cancer. Nat Rev Cancer 2: 489-501, 2002.

32. Altomare DA and Testa JR: Perturbations of the AKT signaling pathway in human cancer. Oncogene 24: 7455-7464, 2005.

33. Datta SR, Dudek H, Tao X, Masters S, Fu H, Gotoh $Y$ and Greenberg ME: Akt phosphorylation of BAD couples survival signals to the cell-intrinsic death machinery. Cell 91: 231-241, 1997.

34. Brunet A, Bonni A, Zigmond MJ, Lin MZ, Juo P, Hu LS, Anderson MJ, Arden KC, Blenis J and Greenberg ME: Akt promotes cell survival by phosphorylating and inhibiting a Forkhead transcription factor. Cell 96: 857-868, 1999.

35. Mayo MW and Baldwin AS: The transcription factor NF-kappaB: Control of oncogenesis and cancer therapy resistance. Biochim Biophys Acta 1470: M55-M62, 2000.

36. Bjornsti MA and Houghton PJ: The TOR pathway: A target for cancer therapy. Nat Rev Cancer 4: 335-348, 2004. 